Keywords: EAT-40; EAT-26; Eating disorders;

Bulimia; Drugs; Substances.

\title{
Eating attitudes and their relation with drug consumption in a university sample
}

\author{
Manuel Herrero, Ph.D.* \\ Conrado M. Viña, Ph.D.* \\ Gustavo Ramírez, Ph.D.** \\ * Department of Personality, Assessment \\ and Psychological Treatments, \\ La Laguna University \\ ** Department of Psychobiology and \\ Behaviour Sciences Methodology, \\ La Laguna University \\ SPAIN
}

\begin{abstract}
Background and Objectives: Some relations between abnormal eating behaviours and attitudes, and other psychiatric disorders have been found in different populations. This study was carried out to examine the relations between eating attitudes and substance use among university students from Spain.

Methods: The EAT and a substance use questionnaire were administered to a sample of 1,089 male and female university students in a cross-sectional design.

Results: There were significant differences in drug consumption between students that met cut-off score criteria for the 40 and 26-item versions, and those that did not. Significant differences also emerged between extreme groups ( 25 vs. 75 percentile) in both EAT versions and in all subscales, especially in the Bulimia and Food Preoccupation subscale. A clearly distinct pattern of differences appeared in male and female students.

Conclusions: Outcomes are in consonance with the theories proposed by several authors to explain the etiological relation between eating disorders and substance use.
\end{abstract}

Received: 20 January 2009

Revised: 7 July 2009

Accepted: 7 September 2009 


\section{Introduction}

High co-morbidity rates between abnormal eating behaviours and attitudes, and other psychological disorders are commonly found in the literature. Anxiety and mood disorders, personality disorders, and substance use and abuse disorders are conspicuous amongst these $\mathrm{e}^{1-8}$.

Regarding substance use, co-morbidity with eating disorders (EDs) have been reported by several authors ${ }^{9-18}$. Recently, it has been pointed out ${ }^{2}$ that $6 \%$ to $55 \%$ of ED patients had substance use disorders. This relation has been found mainly in bulimia nervosa and in patients with the binge-eating/purging type of anorexia nervosa. So, Holderness and her team, in a classical review work of the literature $^{15}$, found that the percentages of bulimics who reported alcohol or drug abuse and/or dependence, ranged from $0 \%$ to $55 \%$ with a median of $17.05 \%$.

These outcomes have also been found in general population studies which selected persons who met DSM diagnostic criteria for eating disorders ${ }^{19-22}$, and in studies using both of these populations, plus a normal student comparison group ${ }^{23-25}$.

To investigate this relation this research team previously carried out a pilot study with university students ${ }^{26}$. Significant correlations between abnormal eating behaviours and attitudes (EAT) and substance use were not found. Nevertheless, there were significant differences between extreme groups ( 25 vs. 75 percentile) in the two EAT versions (40 and 26 items), and in Bulimia and Food Preoccupation (EAT-26).

In the present study, the sample has been enlarged in order to check the results obtained in the pilot study. Moreover, the cutoff scores of the EAT- $40^{27}$ and of the EAT-
$26^{28}$ were used to see if significant differences in substance consumption emerged between the university students who met these criteria (EAT- $40 \geq 30$; EAT-26 $\geq 20$ ) and those who did not.

\section{Methods}

Participants: The sample was composed of 1,089 students from seven faculties of $\mathrm{La}$ Laguna University (Canary Islands, Spain), $890(81.7 \%)$ were females and $195(17.9 \%)$ males (these percentages reflected the composition of the population), and 4 people that did not declare their gender $(0.4 \%)$. The ages ranged from 17 to 45 years old, with a mean of $20.6(\mathrm{sd}=3.5)$. Students were from any of the years of 7 degrees: Psychology, Pedagogy, Speech Therapy, Law, French Philology, Teaching Profession, and Labour Law.

Instruments: Two questionnaires were used in this study. The Eating Attitudes Test, $\mathrm{EAT}^{27}$, and a substance consumption questionnaire $^{29}$. The first instrument, the EAT, contains forty items that are rated on a scale ranging from 0 (never) to 5 (always). These items measure behaviours, feelings and thoughts associated with eating disorders. This questionnaire has been factorized by different authors ${ }^{27,30-32}$. In this work the factor solution obtained in $^{30}$ has been used. These authors obtained three empirical factors with the Spanish version: Dieting and Food Preoccupation, Perceived Social Pressure and Eating Distress, and Psychobiological Disorders. This instrument has a short version, the EAT-26, ${ }^{28}$ which is composed by twenty six items selected from the original version (EAT-40). The authors of the short version obtained three empirical factors: Dieting, Bulimia and Food Preoccupation, and Oral Control. Both versions of the 
test have shown adequate levels of validity and reliability ${ }^{30,33-35}$. In this study the two versions of the EAT have been used for several reasons. From the clinical standpoint, it has been stated ${ }^{36}$ that is more relevant the score of the subscales separately that the global score of an inventory and, as each version of the EAT has different subscales, is advisable to use both. In addition, since both versions have different factor solutions, we were interested in checking on the relative importance of each one of the subscales when the time comes to detect differences in the use of substances and, especially, if the subscale more related to bulimia (Bulimia and Food Preoccupation of the EAT-26) was the one that caused the greater differences. In our pilot study ${ }^{26}$ we also saw that, depending on which version of the EAT was used to form the extreme groups, significant differences in different variables arose from substance consumption. Another important reason to report the results with the two versions of the questionnaire is that it allows to compare these results with other studies that use anyone of them, since science is based, to a great extent, in the accumulation and comparison of data.

The second instrument has been used ${ }^{29}$ in a wide epidemiological study in Madrid (Spain), and is composed of four items that briefly trace the recency and ways of use of some of the most used drugs in the population. The first item inquires whether the student has taken or not at least one alcoholic drink in the last month. The second asks at what age the person began to consume alcohol weekly. The third question is whether the student has smoked more than a hundred cigarettes in his/her life. The fourth question explores the recency of consumption of different substances: tranquilizers without medical prescription, cannabis, cocaine, heroin, amphetamines, and any other drugs not includ- ed in this list. This question is rated on the following scale: 0 (never); 1 (any time in your life); 2 (any time in the last year); and 3 (any time in the last month).

Procedure: Instruments were administered collectively during class hours and were completed voluntarily. Issues regarding anonymity and confidentiality were assured. Participants did not receive any type of incentive for their participation in the study. Only two of the approached people refused to participate. As we had no specific hypotheses about in which substances could arise significant differences between extreme groups formed with EAT variables, we adjusted the accepted significance level to $\mathrm{p}<0.05$.

Statistical analysis: Pearson correlations were used to analyze the relation between EAT and consumption variables. Analyses of variance (ANOVAs) were used in order to analyze mean differences in consumption between the groups with extreme scores in the EAT scales and subscales, and the groups formed by the people that fulfil/non-fulfil the risk criteria of the two EAT versions. All these analyses were carried out through the Statistical Package for Social Sciences (SPSS) for Windows, version 11.5.1.

\section{Results}

Pearson correlations between EAT scales and subscales scores, and the different drugs were calculated, and no correlation emerged with statistical significance. Nevertheless, as in the pilot study mentioned above, it was checked whether there were significant differences in substance consumption between the groups with extreme scores in both EAT versions and their subscales, and between those formed by the cut-off scores criteria. We are 
going to present separately the male and female subsamples since the epidemiological data $^{1}$ clearly indicate that the prevalence of EDs is much higher in the case of women.

The results for women can be seen in Tables 1 and 2 (only substances with significant differences between groups are shown). As can be seen in Table 2, the significant differences arise between extreme groups of the two versions of the EAT (40 and 26 items) in the age of onset of weekly alcohol consumption (women at 75 percentile start before), and in the recency of consumption of tranquilizers without medical prescription, cocaine and amphetamines (this variable only in the EAT-26), with higher recency of consumption in women at percentile 75 (the direction of all the differences that will be commented below is the same).

As to subscales, it can be seen that, in general, the EAT-40 subscales yield a smaller number of significant differences than the EAT-26 subscales. In the former there are significant differences between extreme groups of Perceived Social Pressure and Eating Distress (onset age of alcohol consumption and tranquilizers recency), and of Psychobiological Disorders (cocaine).

Regarding the shortened version of the EAT, there are significant differences between extreme groups of the three subscales. One significant difference (tranquilizers) emerges in Dieting. In the Bulimia and Food Preoccupation subscale there are five significant differences: more than 100 cigarettes smoked in life, age of onset of weekly alcohol consumption; and consumption recency of cocaine, amphetamines, and other drugs. Finally, in Oral Control there are two significant differences between extreme groups: age of onset of weekly alcohol consumption and tranquilizers. Two substances approach statistical significance: cocaine $(p=0.052)$ and amphetamines $(\mathrm{p}=0.051)$.
With regard to the cut-off scores of both versions of the EAT, significant differences appear between women who meet the cutoff score criteria and those who do not. These differences arise in age of onset of alcohol consumption at least once per week; and in recency of consumption of tranquilizers and cocaine.

The differences found in men are not presented in a table as there were only four differences between groups. Alcohol consumption in the last month provokes significant differences between extreme groups in the whole EAT-40 scale [F = 6.99; upper group mean $=0.71(n=45)$, lower group mean $=$ $0.96(n=26)]$ and between groups defined by the EAT-26 cut-off score [F $=5.31$; upper group mean $=0.33(\mathrm{n}=3)$, lower group mean $=0.84(n=135)]$. The other differences are located in the EAT-40 subscales: Dieting and Food Preoccupation (amphetamines) $[\mathrm{F}=4.23$; upper group mean $=0.11$ $(n=55)$, lower group mean $=0.26(n=27)]$, and Psychobiological Disorders (heroin) $[\mathrm{F}$ $=5.36$; upper group mean $=0.04(n=53)$, lower group mean $=0.00(n=138)]$. As can be seen in these results, only in this last variable, does the group with the highest scores present a more recent consumption. In the other three, the differences are in the opposite direction.

\section{Discussion}

In this study, the correlations between eating attitudes and drug consumption pointed out by authors mentioned above have not been found. This outcome may be due to the fact that here a university sample was used, while the other studies used patients or, when general population was studied, individuals who met DSM diagnostic criteria for EDs 


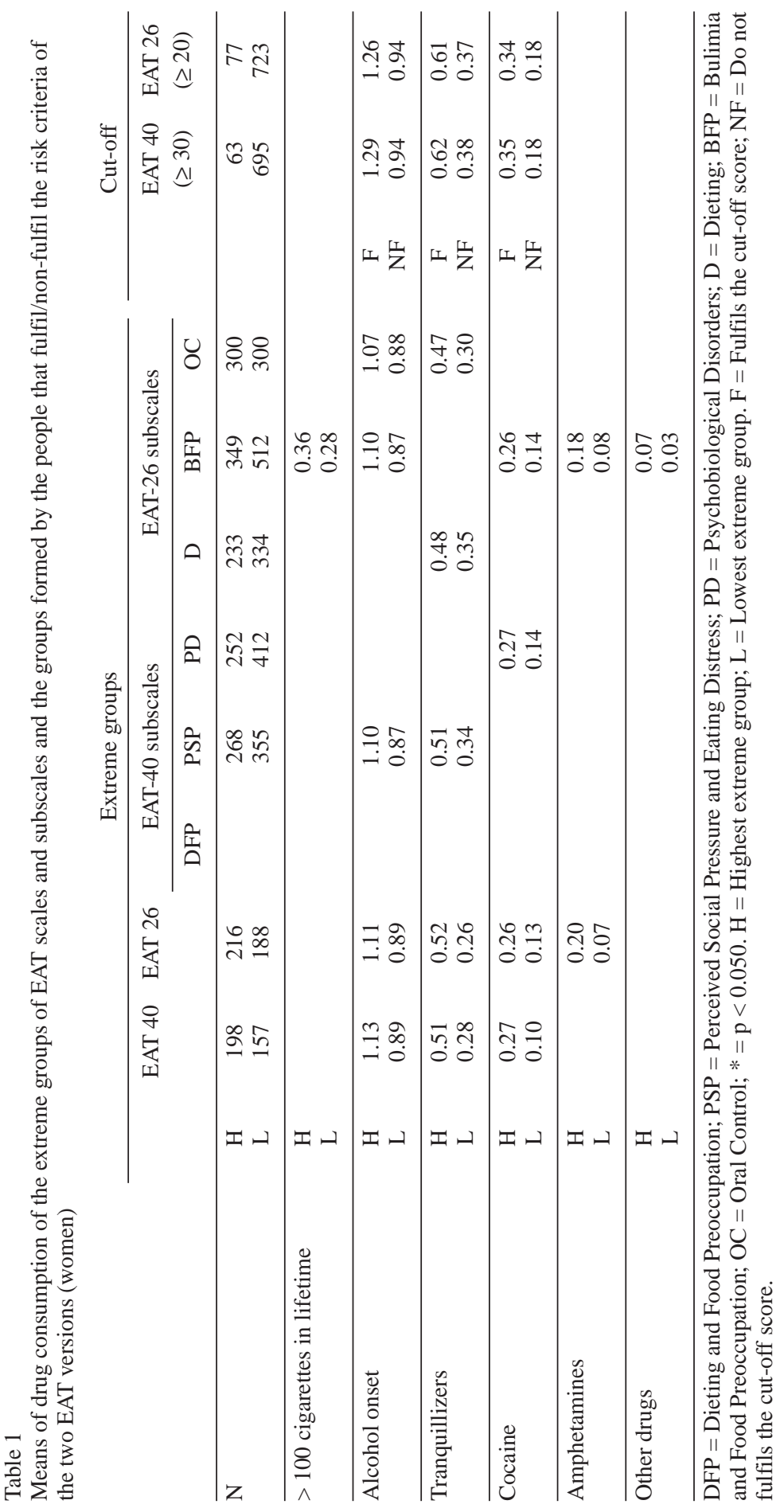




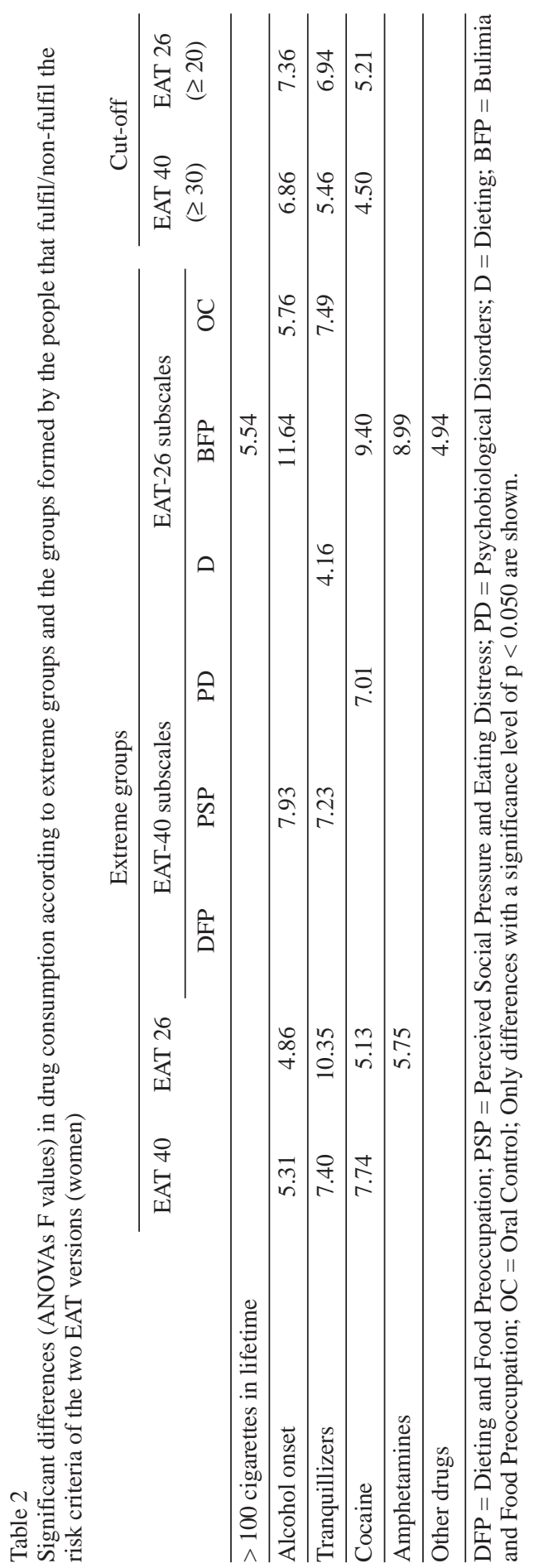

were selected. Nevertheless, when EAT highest and lowest score groups were compared, significant differences emerged in a similar way as in the pilot study ${ }^{26}$. However, in this study, there were significant differences between extreme groups not only in the whole scores of both versions (EAT-40 and EAT-26) and in the Bulimia and Food Preoccupation subscale, but in all the subscales.

Besides, as it has been seen, significant differences appeared between women who met the cut-off score criteria and those who did not, in three consumption variables (onset age of alcohol consumption, tranquilizers and cocaine recency). This particular finding is important for the applied field, since the fulfilment of either of these two criteria proposed by the authors of the EAT (EAT-40 $\geq 30$; EAT-26 $\geq 20$ ) suggests the need to explore substance use, an aspect already pointed out by several authors ${ }^{37,38}$. Moreover, these differences were almost the same as those found between extreme groups ( 25 vs. 75 percentile) in both versions of the EAT, which speaks in favour of the validity of these cut-off scores.

The number of variables with significant differences increased when the extreme groups of the Bulimia and Food Preoccupation subscale were compared. This result agrees with the findings indicated in the introduction to this study, that emphasize the association of psychoactive substance consumption with bulimic behaviours, and can be explained by the theory that alludes to the impulsivity features shared by both kinds of disorder $5,10,15,39,40$.

As to the consumption variables, those that presented a higher number of significant differences were: age of onset of weekly alcohol consumption, and the recency of consumption of cocaine, amphetamines and tranquilizers. According to some of the au- 
thors previously mentioned ${ }^{5}$, the higher lever of cocaine and amphetamines consumption would be explained by the developmental perspective which posits that individuals consume these substances with the aim of achieving and maintaining a shape and weight adjusted to social standards.

On the other hand, the self-medication theory suggests that individuals with EDs use substances in order to cope with eating problems and the preoccupation that these cause. This could explain the higher recency in the use of tranquilizers without medical prescription, and the earlier onset of alcohol consumption, all of these in the group of women with the highest scores in the EAT.

The number of significant differences found in men was clearly lower, and three out of four of these were in the opposite direction to those found in women. On the one hand, this result fits with the gender differences repeatedly found in the literature ${ }^{41-45}$. On the other hand, this result could be explained arguing that, perhaps, in men the cause of substance consumption is more social and, therefore, of a less ED-associated symptomatology.

In general, the findings of this study obtained with self-report instruments in a university sample are in a similar direction to those obtained with clinical samples, and could be useful for further exploration of the causal factors common to both substance use and eating disorders, one of these being the impulsivity factor. Nevertheless, as it has been asserted ${ }^{5}$, assessment instruments such as semi-structured interviews could be useful for more focused empirical investigations aimed at clarifying the etiological relation between eating disorders and substance use. However, much further research will be required before this question is completely clarified, and, as other authors have recently asserted $^{46}$, drug abuse in people with eating disorders is an area of clinical concern that should be monitored routinely. This relation is so important that it has been proposed ${ }^{47} \mathrm{a}$ model of treatment that focus on ways in which therapists can address co-existing eating disorders and drug problems.

Regarding the limitations of the present study, we can mention that from this type of studies conclusions cannot be extracted about the causal direction of the observed relations. One cannot talk about the possible evolution of the people with this type of anomalous behaviours and attitudes (substance consumption and eating) either, as this study is a cross-sectional and no longitudinal one. We also have to mention that the used sample has not been obtained by a procedure of stratified random sampling, although we have to indicate that the sample $(1,089$ people $)$ is important in relation to the total studied population ${ }^{3,20,26}$.

\section{References}

1. American Psychiatric Association. Diagnostic and Statistical Manual of Mental Disorders. 4th ed. Text Revised. Washington, D.C.: American Psychiatric Association; 2000. p. 1049.

2. Blinder BJ, Cumella EJ, Sanathara VA. Pshychiatric comorbidities of female inpatients with eating disorders. Psychosom Med 2006; 68: 454-462.

3. Bulik CM. Anxiety, depression, and eating disorders. In: Fairburn CG, Brownell KD, editors. Eating disorders and obesity. New York: Guilford; 2002. p. 193-198.

4. Granner ML, Black DR, Abood DA. Levels of cigarette and alcohol use related to eating-disorder attitudes. Am J Health Behav 2002; 26(1): 43-55.

5. Wolfe WL, Maisto SA. The relationship between eating disorders and substance use Moving beyond co-prevalence research. Clin Psychol Rev 2000; 20(5): 617-631.

6. Wonderlich SA. Personality and eating disorders. In: Fairburn CG, Brownell KD, editors. Eating disorders and obesity. New York: Guilford; 2002. p. 204-209. 
7. Wonderlich SA, Mitchell JE. Eating disorders and comorbidity: Empirical, conceptual, and clinical implications. Psychopharmacol Bull 1994; 33(3): 381-390.

8. Zaider TI, Johnson JG, Cockell SJ Psychiatric comorbidity associated with eating disorder symptomatology among adolescents in the community. Int $\mathrm{J}$ Eat Disord 2000; 28(1): 58-67.

9. Bapt N, Flament M, Mammar N, Paterniti S, Venisse JL, Miocque D, et al. Boulimie et autres addictions (alcool, drogues illicites, médicaments psychotropes) [Bulimia and other adictions (alcohol, illegal drugs, psychotropic drugs)]. In: Flament M, Jeammet P, editors. La boulimie. Paris: Masson; 1999. p. 173-186.

10. Bulik CM, Sullivan PF, Carter FA, Joyce PR. Lifetime comorbidity of alcohol dependence in women with bulimia nervosa. Addict Behav 1997; 22: 437-446.

11. Bonfà F, Cabrini S, Avanzi M, Bettinardi O, Spotti $\mathrm{R}$, Uber E. Treatment dropout in drug-addicted women: Are eating disorders implicated? Eat Weight Disord 2008; 13(2): 81-86.

12. Corcos M, Nezelof S, Speranza M, Topa S, Girardon $\mathrm{N}$, Guilbaud O, et al. Psychoactive substance consumption in eating disorders. Eat Behav 2001; 2(1): 27-38.

13. Haug NA, Heinberg LJ, Guarda AS. Cigarrette smoking and its relationship to other substance use among eating disordered inpatients. Eat Weight Disord 2001; 6: 130-139.

14. Herzog DB, Frank DL, Dorer DJ, Keel PK, Jackson S, Manzo MP. Drug abuse in women with eating disorders. Int J Eat Disord 2006; 39(5): 364-368.

15. Holderness CC, Brooks-Gunn J, Warren MP. Comorbidity of eating disorders and substance abuse review of the literature. Int J Eat Disord 1994; 16(1): 1-34.

16. Matsumoto T, Kosaka K, Yamaguchi A, Minami K, Endo K, Yabana T, et al. Eating disorders in female substance use disorders: A preliminary research on the relationship of substances and eating behaviors. Seishin Igaku (Clinical Psychiatry) 2004; 45(2): 119-127.

17. Striegel-Moore RH, Garvin V, Dohm FA, Rosenheck RA. Eating disorders in a national sample of hospitalized female and male veterans: Detection rates and psychiatric comorbidity. Int J Eat Disord 1999; 25: 405-414.

18. Wiederman MW, Pryor T. Substance use among women with eating disorders. Int J Eat Disord 1996; 20(2): 163-168.

19. Dansky BS, Brewerton TD, Kilpatrick DG. Comorbidity of bulimia nervosa and alcohol use disorders: Results from the National Women's Study. Int J Eat Disord 2000; 27(2): 180-190.
20. Dohm FA, Striegel-Moore RH, Wilfley DE, Pike KM, Hook J, Fairburn CG. Self-harm and substance use in a community sample of black and white women with binge eating disorder or bulimia nervosa. Int J Eat Disord 2002; 32(4): 389-400.

21. Dunn EC, Larimer ME, Neighbors C. Alcohol and drug-related negative consequences in college students with bulimia nervosa and binge eating disorder. Int $\mathrm{J}$ Eat Disord 2002; 32(2): 171-178.

22. Garfinkel PE, Lin E, Goering P, Spegg C, Goldbloom DS, Kennedy S, et al. Purging and non purging forms of bulimia nervosa in a community sample. Int J Eat Disord 1996; 20(3): 231-238.

23. Krug I, Treasure J, Anderluh M, Bellodi L, Cellini E, Di Bernardo M, et al. Present and lifetime comorbidity of tobacco, alcohol and drug use in eating disorders: A European multicenter study. Drug Alcohol Depen 2008; 97(12): 169-179.

24. Stock SL, Goldberg G, Corbett S, Katzman DK. Substance use in female adolescent with eating disorders. $\mathrm{J}$ Adol Health 2002; 31(2): 176-182.

25. Thompson MG, Schwartz DM. Life adjustment of women with anorexia nervosa and anorexic-like behaviour. Int J Eat Disord 1982; 1: 47-60.

26. Herrero M, Viña CM. [Eating attitudes and behaviours, and their relation with drug consumption: A university sample]. Análisis y Modificación de Conducta (Behaviour Analysis and Modification) 2002; 28(121): 645-670.

27. Garner DM, Garfinkel PE. The Eating Attitudes Test: An index of the symptoms of anorexia nervosa. Psychological Medicine 1979; 9: 273-279.

28. Garner DM, Olmsted MP, Bohr Y, Garfinkel RE. The Eating Attitudes Test: Psychometric features and clinical correlates. Psychol Med 1982; 12: 871-878.

29. Gandarillas A, Febrel C. [Eating disorders prevalence survey on school adolescents from the Community of Madrid] Encuesta de prevalencia de trastornos del comportamiento alimentario en adolescentes escolarizados de la Comunidad de Madrid. Madrid: Dirección General de Salud Pública; 2000.

30. Castro J, Toro J, Salamero M, Guimerá E. The Eating Attitudes Test: Validation of the Spanish version. Psychol Assess 1991; 7(2): 175-190.

31. Eisler I, Szmukler GI. Social class as a confounding variable in the Eating Attitudes Test. J Psychiat Res 1985; 19: 171-176.

32. Wells JE, Coope PA, Gabb DC, Pears RK. The factor structure of the Eating Attitudes Test with adolescent schoolgirls. Psychol Med 1985; 15: 141-146. 
33. Álvarez-Rayón G, Vázquez-Arévalo R, MancillaDíaz JM, Gómez-Peresmitre G. [Evaluation of psychometric properties of the Eating Attitudes Test (EAT-40) in Mexican women]. Evaluación de las propiedades psicométricas del Test de Actitudes Alimentarias (EAT-40) en mujeres Mexicanas. Revista Mexicana de Psicología (Mexican Journal of Psychology) 2002; 19(1): 47-56.

34. Gross J, Rosen JC. Bulimia in adolescents: Prevalence and psychosocial correlates. Int J Eat Disord 1988; 7 : 51-61.

35. Rosen JC, Srebnick D. Assessment of eating disorders. In: McReynolds P, Rosen JC, Chelune GJ, editors. Advances in Psychological Assessment. New York: Plenum Press; 1990. Vol 7; p. 229-260.

36. Fernández-Aranda F, Turón-Gil V. Trastornos de la alimentación: Guía básica de tratamiento en anorexia y bulimia. Barcelona: Masson; 1998.

37. Mitchell JE, Specker S, Edmonson K. Management of substance abuse and dependence. In: Garner DM, Garfinkel PM, editors. Handbook of treatment for eating disorders. New York: The Guilford Press; 1997. p. 415-423.

38. Neumark-Sztainer D, Story M, Dixon LB, Murray DM. Adolescents in engaging in unhealthy weight control behaviors: Are they at risk for other health compromising behaviors? Am J Public Health 1998; 88: 952-955.

39. Krahn DD, Kurth C, Demitrack M, Drewnowski A. The relationship of dieting severity and bulimic behaviors to alcohol and other drug use in young women. J Subst Abuse 1992; 4: 341-353.

40. Suzuki K, Higuchi S, Yamada K, Komiya H, Takagi S. Bulimia nervosa with and without alcoholism a comparative study in Japan. Int J Eat Disord 1994; 16: 137-146.

41. Franco KS, Tamburrino MB, Carrol BT, Bernal GA. Eating attitudes in college males. Int J Eat Disord 1988; 7(2): 285-288.
42. Leichner P, Arnett J, Rallo JS, Srikameswaran S, Vulano B. An epidemiologic study of maladaptated eating attitudes in a Canadian school age population. Int $\mathrm{J}$ Eat Disord 1986; 5: 969-982.

43. Raich RM, Rosen JC, Deus J, Pérez O, Requena A, Gross, J. Eating disorder symptoms among adolescents in the United States and Spain: A comparative study. Int J Eat Disord 1992; 11(1): 63-72.

44. Rosen JC, Silberg NT, Gross J. Eating Attitudes Test and Eating Disorders Inventory: Norms for adolescent girls and boys. J Consult Clin Psychol 1988; 56(2): 305-308.

45. Silberstein LR, Striegel-Moore RH, Timko C, Rodin J. Behavioral and psychological implications of body image dissatisfaction: Do men and women differ? Sex Roles 1988; 19: 219-232.

46. Franko DL, Dorer DJ, Keel PK, Jackson S, Manzo MP, Herzog DB. Interactions between eating disorders and drug abuse. J Nerv Ment Dis 2008; 196(7): 556-561.

47. Coelho JS, Thornton C, Touyz SW, Lacey JH, Corfe $\mathrm{S}$. Eating disorders and drug and alcohol problems. In: Baker A, Velleman R, editors. Clinical handbook of co-existing mental health and drug and alcohol problems. Florence (K): Routledge; 2007. p. 290-308.
Address for correspondence:
Manuel Herrero
Department of Personality, Assessment and Psychological Treatments and Faculty of Psychology
University of La Laguna
S/C Tenerife, Canary Islands
(Spain)
Tel: (+34) 922317448
Fax: (+34) 922317461
E-mail: mherrero@ull.es 